\title{
Atos de profanação
}

\author{
Profanation acts
}

Sílvia Fernandes

Sílvia Fernandes

Professora titular sênior do Programa de Pós-Graduação em Artes Cênicas da Escola de Comunicação e Artes da Universidade de São Paulo (ECA/USP)

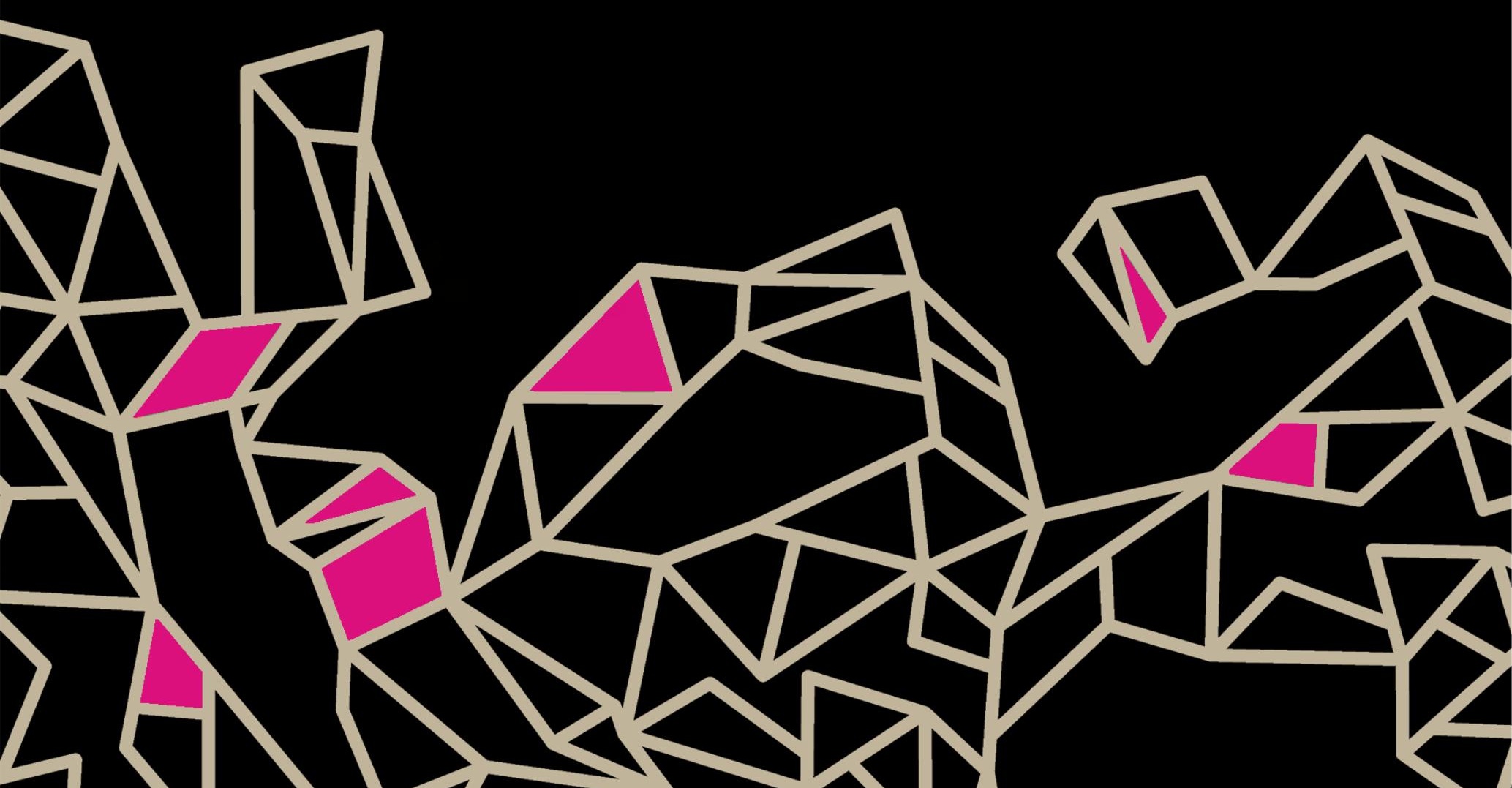




\section{Resumo}

Este artigo analisa as últimas criações de Janaína Leite feitas ao longo da década de 2010. Conversas com meu pai, estreado em 2014, e especialmente Stabat Mater, apresentado pela primeira vez, ainda em processo de criação, em 2019, são índices da radical trajetória da artista, e refletem uma série de experimentos cênicos e políticos recorrentes em uma parcela do teatro brasileiro do século XXI.

Palavras-chave: Janaína Leite, Stabat Mater, Profanação.

\section{Abstract}

This article analyzes the latest creations made by Janaina Leite during the second decade of the 2000s. Conversas com meu pai (lit. Conversations with my father) which premiered in 2014, and Stabat Mater, presented for the first time and still being developed in 2019, are signs of the artist's radical trajectory. They reflect a series of recurring scenic and political experiments in 21st century Brazilian theater.

Keywords: Janaína Leite, Stabat Mater, Profanation.

As últimas criações de Janaína Leite, feitas ao longo dos anos 2010, são índices radicais da trajetória da artista. Conversas com meu pai, estreado em 2014, e Stabat Mater, apresentado pela primeira vez, ainda em processo de criação, em 2019, refletem uma série de experimentos cênicos e políticos recorrentes em uma parcela do teatro brasileiro do século XXI.

A dívida dessas criações com o teatro de grupo é inegável. O trabalho de Janaína com o XIX de Teatro sem dúvida é caudatário dos processos colaborativos que emergiram com força no último decênio. Sua importância deve-se especialmente à horizontalidade da prática teatral, que franqueou tomadas democráticas de decisão sobre a cena, permitindo aos participantes decidir os rumos do que pretendiam criar nos palcos ou nas cidades.

O XIX foi um dos coletivos mais importantes a ocupar espaços urbanos no período, no caso a Vila Maria Zélia, em São Paulo, que escolheu para contracenar e potencializar temáticas políticas como as lutas feministas no país, cada vez mais fortalecidas. Em Histeria, por exemplo, a posição subalterna da mulher na sociedade patriarcal, misógina e excludente, explicitava-se na opção 
por separar os espectadores entre mulheres e homens e no diálogo profícuo sobre os problemas do feminino. Sem dúvida, a conformação espacial potencializava não apenas o necessário convívio entre mulheres, mas exibia o preconceito que sempre acompanhou as histéricas, até certo ponto reabilitadas pela psicanálise de Freud, para quem elas padeciam de reminiscências, incrustando a memória traumática no próprio corpo.

No enfrentamento da discussão do feminino no coletivo que criou, Janaína preparava-se para a experiência futura, ainda que sem o saber. Em Festa de separação, trabalho feito em parceria com o ex-marido, a posição da mulher explicitava-se na ritualização do fim de um casamento. $O$ casal compartilhava com o espectador os desencontros da vida a dois e, mais que isso, comemorava o fim, como se quisesse atualizar na performance os pressupostos de Spinoza acerca da vitalidade das afecções alegres em detrimento da tristeza que paralisa a ação.

Ao festejar o final da união compartilhando documentos, registros e testemunhos da vida a dois, Janaína Leite fortalecia uma forte tendência da cena contemporânea que recebeu vários nomes de batismo, todos indicando dispositivos cênicos que pretendiam, paradoxalmente, diluir a mediação teatral: teatro documentário, autoficção, auto mise en scène, autorrepresentação, performance autobiográfica ou autoescritura performativa (termo escolhido por ela para se referir ao próprio trabalho), foram algumas das palavras-chave que proliferaram nos estudos do período que tentam decifrar o que faziam os criadores. As muitas nomeações dessa cena desviante, híbrida, incapaz de separar com clareza a vida da representação e a política da estética foram empregadas por teóricos para analisar práticas performativas que utilizam depoimentos, documentos, relatos de vida, testemunhos e fragmentos memoriais ligados à trajetória biográfica dos autores. E que são indícios do que Maryvonne Saison definiu como "teatros do real" ao analisar algumas vertentes das artes da cena do final do século XX1.

1 No livro Les théâtres du réel (1998) Maryvonne Saison observa que determinados artistas problematizam as práticas de representação tencionando que o espectador seja colocado em confronto direto com as questões tratadas em cena, numa espécie de reivindicação de acesso imediato ao real, definido a partir da distinção entre Vorstellung (representação) a Darstellung (apresentação), na tentativa de designar a colocação em presença da própria coisa. Aceitando-se ou não seus argumentos, é inegável que uma parcela considerável das práticas artísticas contemporâneas opta por mecanismos de confronto da representação com experiências testemunhais, depoimentos, cartas e entrevistas, como comprova a explosão de formas inéditas de teatro documentário, mapeadas exaustivamente na coletânea Les théâtres documentaires, organizada por Erika Magris e Béatrice Picon-Vallin (2019). 
As muitas vias de aproximação do teatro com o real foram responsáveis pelo deslocamento das práticas teatrais em direção a uma cena performativa, de contornos fluidos e localização imprecisa, que Janaína pratica de modo radical. Sem dúvida o que experimenta é um novo modo de teatro político, que não pretende reproduzir a realidade por meio do realismo ou de narrativas críticas, no intuito de discuti-la com aparatos lógicos e analíticos. Desviando-se desses pressupostos, seu desejo do real em cena parece ter relação íntima com a politização do teatro e da performance nas lutas identitárias, que acontece com mais força no princípio do século XXI, quando as estratégias de ação micropolítica são diversificadas e, muitas vezes, não chegam a ser lidas como posicionamentos políticos, tal a força e a persistência dos modelos canônicos.

Mas basta assistir a suas criações para olhar o teatro político por ângulos inéditos. É o caso de trabalhos corajosos como Conversas com meu pai, cuja versão final é de Alexandre Dal Farra, no qual enfrenta um dos núcleos explosivos da vida de qualquer mulher. Na retomada da vertente autobiográfica, examina a relação com seu pai. Sem deixar de assumir a carga ficcional que as lembranças supõem, recorre à memória pessoal para acertar contas com aquele que lhe deu à luz, mas também à sombra, e com quem se comunicou nos últimos anos por meio de bilhetes. De fato, a vida lhe ofereceu a melhor metáfora da relação com o pai. A traqueostomia que o impedia de falar e a surdez temporária que a acometeu certamente constituíam a imagem precisa de uma relação truncada, em que a comunicação muitas vezes se confundia com a agressão. E com a impossibilidade de escuta. Nesse sentido, é impressionante a passagem do texto em que a autora recorda o assassinato da gata de estimação, morta por afogamento e marteladas pelo pai enfurecido. A remissão à cena célebre de Nelson Rodrigues não escamoteia a violência do homem contra a mulher, que não poderia ganhar síntese mais precisa.

Recentemente, a problemática do real no teatro foi discutida por pesquisadores como Carol Martin, para quem os teatros do real do século XXI materializam considerações públicas sobre diversos aspectos da realidade, além de priorizarem o recurso a testemunhos, por acreditar que os indivíduos são arquivos vivos de fala, comportamento e experiência. (MARTIN, 2013). Entre os estudos sobre o tema feitos no Brasil destaca-se o de Janaína Leite, Autoescrituras performativas: do diário à cena (2017). 
No experimento, insistindo em mesclar documental e autobiográfico, a artista atravessa uma nova fronteira do acerto de contas entre teatro e vida. O tema prospectado em si própria, na exploração arriscada do passado traumático, torna ainda mais indistintas as fronteiras entre real e ficcional. Mas a essa altura já não faz sentido perguntar se o incesto aconteceu de fato, pois o trauma da lembrança basta. Ao recorrer à narrativa bíblica das filhas de Ló e ao mito de Édipo, Janaína admite as ficções que a memória cria e, na esteira de Freud, assume que o abuso sexual não é menos sofrido por ser, talvez, fantasia. Ao mesmo tempo, esboça a narrativa da agressão como nos sonhos, de modo cifrado, por meio de um "jogo de exposição e ocultação", como observa Jorge Louraço em texto sobre o espetáculo (LOURAÇO, 2014).

Portanto, não se trata apenas de fazer um depoimento pessoal do modo mais sincero possível, como acontece em outras tentativas de performance autobiográfica. Janaína recorre à teatralidade ostensiva, entendida como uso premeditado da mediação e de aparatos cênicos que funcionam como espécies de notas de rodapé destinadas a viabilizar o distanciamento do espectador e, ao mesmo tempo, desestabilizá-lo com irrupções de real e risco performativo².

Materiais artísticos, filosóficos, literários e científicos convivem para potencializar a experiência, filiando a criadora à corrente artística que compreende a arte como forma de pesquisa. Trata-se de uma trajetória de vida, mas também de reflexão. Ambas recuperadas nas recordações, quem sabe verdadeiras, reorganizadas e tornadas ficção no sentido defendido por Jacques Rancière, para quem a ficção não é a criação de um mundo imaginário oposto ao real, mas "um trabalho que realiza dissensos, que muda os modos de apresentação sensível e as formas de enunciação [...] construindo

2 A respeito do que chamo de aparatos cênicos, é interessante constatar o retorno do que se poderia considerar uma teatralidade ostensiva, em que os dispositivos de mediação ganham maior força. É o que nota André Eiermann quando recorre ao conceito de teatro "pós-espetacular" para destacar a emergência de formas de crítica da presença, do "relacional" e da "imediatez" com a criação de modos cênicos que tentam expor novamente as divisões e em que a ordem simbólica volta a intervir como um terceiro que "questiona a representação da comunidade imediata encarnada na imagem da comunicação cara a cara" (EIERMANN, 2012, p. 16). Sobre a mesma questão, merece destaque a reflexão de Júlia Guimarães sobre as mediações espetaculares que retornam, nos últimos anos, com extrema força e promovem um deslocamento das experiências cênicas rumo a uma teatralidade insólita, viabilizada por jogos performativos que entrecruzam a materialidade da cena com construções altamente metafóricas (Guimarães, 2020). 
relações novas entre a aparência e a realidade, o singular e o comum, o visível e sua significação" (RANCIÈRE, 2014, p. 64)3.

É o que acontece em Stabat Mater. A mãe denegada do espetáculo anterior reaparece agora como presença/ausência, conforme observação arguta de Luciana Romagnolli em crítica sobre o trabalho (ROMAGNOLLI, 2020). De fato, a mãe está lá, mas não está. A invisibilidade materna nos processos psíquicos da artista, latente em toda a performance, é figurada na posição de Amália Fontes Leite em cena, discreta, encoberta, feita de interferências breves que se assemelham a um testemunho passivo da insurreição da filha. Enquanto o corpo de Janaína expõe-se como objeto de fetiche e sacrifício, o de Amália se oculta sob um manto vermelho, como nota Maria Eugênia de Menezes (MENEZES, 2019).

Mas a figura calma de Amália parece ressoar uma "resistência antiga" capaz de sustentar a performatividade profana da filha, que degola o corpo da mãe para diferenciar-se dela e da herança de submissão que recebeu. A ideia de conflito na transmissão da feminilidade e a necessidade de rejeitar o legado materno para livrar-se da identificação nascida sob o "selo narcísico do idêntico", que orientou a criação, exige o matricídio simbólico. Ele é executado sobre a mesa de conferência em que a performer inicia a apresentação, como um sacrifício da "mascarada feminina" que a sociedade patriarcal e misógina moldou por vários séculos e que é preciso extirpar.

Fiel à intenção de enfrentar as contradições do feminino, Janaína retoma em Stabat Mater a ideia de obsceno. Influenciada pelas leituras de Hal Foster, trabalha a distinção entre o pornográfico, aquele que encena demais na pressuposição do olhar do outro, e o que está "fora de cena" e por isso consegue romper o anteparo da imagem. É pela via da experiência cênica que a performer tenta responder se esse "fora de cena" é possível, já que a moldura teatral sempre supõe o enquadramento da linguagem e a compressão dos experimentos mais radicais no campo do simbólico. É por considerar o obsceno

3 Jacques Rancière desenvolve a questão em diversos textos, como "Paradoxos da arte política", em que concebe a ficção como um trabalho que muda as coordenadas do representável, a percepção dos acontecimentos sensíveis e a maneira de relacioná-los com os sujeitos. "As formas da experiência estética e os modos da ficção criam assim uma paisagem inédita do visível, formas novas de individualidades e conexões, ritmos diferentes de apreensão do que é dado, escalas novas" (RANCIĖRE, 2014, p. 85). 
uma espécie de margem do real que recorre a ele para exprimir aquilo que não é possível simbolizar. E elege o corpo da mãe como uma espécie de abismo que ameaça dissolver as constituições mais arcaicas, verdadeira síntese do desejável e do abjeto. Prospectado a partir de Julia Kristeva e Hal Foster, o conceito retoma a relação entre corpo materno e lei paterna, horror e abjeção: "o abjeto seria a condição em que a subjetividade é perturbada e o sentido entra em colapso". E a obscenidade é o que resta "quando o teatro perde suas bordas", observa Janaína ${ }^{4}$.

A experimentação dos conceitos pesquisados gera os núcleos mais incômodos da performance. E aparece, por exemplo, quando Amália assiste a um ato de sexo explícito de Janaína, gravado e exibido aos espectadores. $\mathrm{Na}$ cena mediada pela tela é evidente que o jogo é o modo privilegiado de enfrentamento do trauma. Contracenando com um profissional do mercado pornográfico, a performer consegue transformar a relação em "puro meio" ao emancipar a prática de uma finalidade e devolver o sexo a um uso não mapeado. Sem dúvida, o que vemos é uma atividade que "esqueceu alegremente o seu objetivo [...] podendo agora exibir-se como tal, como meio sem fim" (AGAMBEN, 2007, p. 74-75).

A penetração mecânica, recidiva, sem fingimentos eróticos, a iluminação clara exibindo o vaivém do ato em várias posições, como peças encaixadas de um lego inusitado, as máscaras usadas pelos parceiros no jogo de desmistificação da pornografia/mercadoria impedem o profissional de se refugiar nos estereótipos do gênero, colocando-o à mercê de uma situação que não domina (não por acaso, abandonou o processo antes da estreia). O que se vê na sequência gravada é o corpo supliciado agora no controle, na expressão certeira de Daniele Ávila Small (2019). E a mãe sentada ao lado da filha, testemunha da profanação até o fim. "A todo momento, a cada passo,

4 No sempre citado O retorno do real, Hal Foster recorre a Jacques Lacan para definir o real em termos de trauma: "Lacan define o traumático como um encontro faltoso com o real. $\mathrm{Na}$ condição de faltoso, o real não pode ser representado, só pode ser repetido; aliás, tem de ser repetido". De certo modo, o real é a negativa do simbólico, "um encontro faltoso, um objeto perdido" (2014, p. 137). No obsceno, prospectado a partir de Georges Bataille, Foster vê o olhar-objeto "apresentado como se não houvesse uma cena para encená-lo, uma moldura da representação para contê-lo, nenhum anteparo" (2014, p. 144). Já a arte abjeta seria atraída para as "fronteiras derrubadas do corpo violado" e, com frequência, esse corpo é o materno (2014, p. 145-146). Janaína Leite retoma essas questões em textos de trabalho inéditos citados nessa passagem. 
eu achava que ela ia recuar, abandonar tudo isso aqui e que talvez eu tivesse pedido demais, esperado demais dela. [...] Mas não podia ser mais óbvio o nosso desfecho. Claro, ele partir e ela ficar. Mais uma vez, Stabat Mater.'

De fato, a mãe é a primeira espectadora da profanação. Pois, como bem diz Janaína, a intenção é unir maternidade e desejo, pureza e pornografia para refletir, distorcer e realizar a inversão simbólica das representações do feminino. E nessa opção, Júlia Kristeva é a parceira preferencial da desconstrução da imagem da maternidade colada às mulheres através dos séculos, que teima em se manter nos anos 2000. Autora basilar para o projeto, Kristeva vê o lugar da mulher como um inquietante ponto cego moldado na fusão entre o feminino e o maternal, que considera um dos pilares do cristianismo e da demarcação de gênero no Ocidente. Nesse sentido, o mito da concepção sem sexo e da perpétua virgindade de Maria - "não mais mãe do homem ou mãe do Cristo, mas mãe de Deus" - é o eixo simbólico de estruturação do corpo feminino. E das profanações que a performer realiza para desmascarar as mitologias que figuram a mulher como receptáculo da semente masculina, na absorção do feminino pelo maternal "que negligencia o que possa querer ou dizer uma mulher" (KRISTEVA, 1988, p. 272).

De fato, a consagração do corpo feminino como "corpo para o outro", mero continente para gestar o filho, perpassa o argumento de Kristeva em Stabat Mater. No texto em que Janaína se inspira, a filósofa recupera as representações da mãe de Cristo desde a tradição católica dos hinos que se disseminaram a partir do século XIII, com a presença recorrente de Maria nas várias estações do calvário. Na maioria delas, a mulher que reúne as funções de mãe, esposa e filha configura "uma gama que vai da sublimação ao ascetismo e ao masoquismo", mas é recompensada com a ascensão. Kristeva comenta que vemos esboçar-se aí uma totalidade ideal em que a especificidade do corpo feminino se anula, e que nenhuma mulher pode encarnar (KRISTEVA, 1988).

As representações concentradas na mãe virgem, que concebeu "sem homem nem sexo", são analisadas por Kristeva como estratos de idealização da figura da mulher ao longo dos séculos, verdadeiro protótipo de construção do feminino no Ocidente. Síntese de maternidade, santidade e passividade, misto de abnegação e doação, a mãe ajoelhada aos pés do Cristo transforma-se em 
núcleo imaginário de uma ordem simbólica e social. E incomoda profundamente uma pensadora como Simone de Beauvoir, que vê nela um índice da derrota feminina. Já Kristeva vislumbra na imagem de Maria o orgulho daquela que "sabe-se votada a essa eternidade (espiritual ou da espécie) que nenhuma mãe inconscientemente ignora"5 (KRISTEVA, 1988, p. 281).

Na performance, Janaína retoma o argumento, ao qual acrescenta o material autobiográfico que sempre sustentou suas criações, compondo uma dramaturgia "em espiral" a partir de diversas figurações do feminino. $\mathrm{Na}$ apresentação mapeia a condição passiva da mulher desde os contos de fada até a cultura de massa contemporânea, especialmente os filmes de terror, que dão continuidade à narrativa do corpo feminino como receptáculo de deuses e monstros. Empilhando referências, associa o deus grego da fecundidade, Príapo, ao vilão da série de filmes Halloween, Michael Myers, para tramar um emaranhado de situações do poder masculino. $O$ pênis ereto da divindade grega e o facão do assassino mascarado são aproximados para compor um núcleo simbólico recidivo, que remete à lei do pai.

$\mathrm{Na}$ tentativa de desarmar esse arranjo ideológico, a performer fricciona erotismo, obscenidade, morte e maternidade em mergulho autobiográfico e reflexivo que endereça ao espectador de modo violento e lúdico. O pacto performativo é estipulado desde o início e não admite grandes hesitações. Da mesma forma que a mãe, o espectador precisa estar lá como testemunha da profanação. E deve compartilhar o imaginário feminino exposto em carne viva, que abala de um modo difícil de descrever. Talvez porque o exercício de remexer traumas e tabus tenha semelhança com a parresía e deslize do ser ao parecer da verdade, como faz Janaína e como explicita Michel Foucault ao analisar o conceito. Para o filósofo, a ideia de expressão da verdade na Grécia pré-socrática implica um comprometimento daquele que diz com o que é dito e tem potência de transformá-lo, como acontece nas ações performativas, que alteram o estatuto do atuante. Daí vem o risco para aquele que fala, que pode ser confrontado com a reação adversa do ouvinte, como também acontece na performance. Nesse sentido, é interessante constatar que as narrativas

5 Devo a lembrança de Simone de Beauvoir a Janaína Leite, que compara as impressões da filósofa sobre a mãe de Cristo às de Julia Kristeva no texto inédito "O Stabat Mater de Julia Kristeva - teoria e dor", 2019. 
testemunhais, comuns nos relatos autobiográficos, nesse caso implicam fortemente aquele que as ouve e vê, como se a coragem da verdade exigisse o desassombro do espectador. A impressão que se tem em Stabat Mater é que dizer a verdade não basta. É preciso alguém que suporte ouvi-la ${ }^{6}$.

A coragem da autoexposição convive com o dispositivo intelectual da conferência que abre a apresentação, mostrando a excelente pesquisadora que Janaína Leite sempre foi, capaz de abrir trilhas insuspeitadas nos assuntos que escolheu. A mesa de palestra, o copo de água, as anotações, a apresentação da pesquisa em tom didático, a exibição de vídeos com documentos e informações sobre o processo e a luz aberta para clarear a exposição das ideias apresentam a autora em plena posse de seu método de investigação, que gerou a performance. Os materiais de criação são expostos desde o teste de elenco até fragmentos de dramaturgia, estudos de cena, anotações, documentos, objetos usados em outros experimentos, sonhos, músicas de Conversas com meu pai e o diário que escreveu por mais de vinte anos. São modos de compartilhar com o espectador processos e meios de trabalho, numa espécie de crítica genética feita ao vivo pela própria artista.

Mas a reflexão acontece a partir de obsessões íntimas. E, sem dúvida, o impacto mais forte vem das pulsões desencadeadas em uma torrente que arrasta o espectador na vivência do feminino, entre "desejo e anestesia", na violência do estupro, do sexo explícito, das dores do parto, da maternidade diferencial de mãe e filha, mãe e filho. E nesse vínculo primordial, posto em cena, aparece a culpa da mãe distraída, incapaz de proteger o filho de uma queda perigosa, na sequência belíssima em que Janaína estira uma corda até o limite girando no vazio diante do risco. "Entendi algo sobre a maternidade - se a corda afrouxa é a mãe que cai”.

6 Segundo Michel Foucault, "para que haja parresía é preciso que, no ato de verdade, haja [...] manifestação de um vínculo fundamental entre a verdade dita e o pensamento de quem disse. [...] Ela implica uma certa forma de coragem, coragem cuja forma mínima consiste em que o parresiasta se arrisque a desfazer, a deslindar essa relação com o outro que tornou possível precisamente seu discurso. [...] E é assim que se estabelecerá o verdadeiro jogo de parresía, a partir dessa espécie de pacto que faz que, se o parresiasta mostra sua coragem dizendo a verdade, contra tudo e contra todos, aquele a que essa parresía é endereçada deverá mostrar sua grandeza de alma aceitando que lhe digam a verdade. Essa espécie de pacto entre aquele que assume o risco de dizer a verdade e aquele que aceita ouvi-la está no cerne do que se poderia chamar de jogo parresiástico" (FOUCAULT, 2011, p. 12-13). 
A relação retorna na apresentação do parto reverso, que mostra o nascimento do filho de Janaína, gravado e exibido em rewind, com o bebê voltando ao útero materno. No vídeo, o espectador ouve vozes e vê duas mãos que tiram o recém-nascido do colo da mãe. "Na sequência, os pés, as pernas, o tronco e a cabeça do bebê penetram a vagina, que volta a se fechar." É difícil narrar o impacto da imagem do bebê ensanguentado reintroduzido nas entranhas escancaradas, com o cordão umbilical tragado de volta e a expressão do rosto materno recuando do alívio às "dores que nunca imaginou fazerem parte da experiência de parir.'A sequência perturba o ideal de pureza do nascimento de um filho, além de desmontar a associação entre santidade e maternidade.

A desconstrução reaparece na narrativa do estupro, quando a mãe não estava lá para proteger a filha, preterida pelo cuidado do marido. Nesse sentido, é impactante o texto em que Janaína relata o abuso ocorrido no dia 8 de agosto de 1996 e registrado no diário de menina de 15 anos, ameaçada com um facão no pescoço e violentada em um matagal, a caminho da escola. Em cena, Amália apresenta ao espectador os vestígios da violência - a página do diário, o boletim de ocorrência, o retrato falado do agressor desenhado por ela, a pedido da filha. "O facão foi se metamorfoseando ao longo da vida, saindo da mão do cara que me pegou, passando pela do meu pai, indo para a minha, mudando seus carrascos, seus sentidos", lembra a autora.

Ao mesmo tempo que ouvimos a narrativa da experiência traumática assistimos à cena de sedução da pole dancer grávida que se exibe ao próprio pai. A sequência veio de um sonho registrado no diário, que descreve uma boate onde se apresenta um show pornográfico de homens com falos gigantes e rostos escondidos por máscaras. Na continuidade da ação, a sonhadora olha para trás e vê o pai sentado em uma mesa, segurando uma faca. Decide então subir ao palco e apresentar uma dança sensual apenas para ele, com os cabelos soltos, o ventre saliente, mascarada numa "figura híbrida entre masculino e feminino" que exorciza "a imagem que há anos a assombrava".

O procedimento arriscado de autoexame, espécie de vivissecção, desloca os lugares imaginários e sociais da mulher, atravessados por ideais de maternidade, santidade e abnegação. $O$ disfarce e o desmascaramento, a teatralidade e a performance, o encenado e o real, indiscerníveis, são procedimentos que visam à profanação, que para Giorgio Agamben é a "tarefa 
política da geração que vem". Para o filósofo, profanar é o ato de devolver as coisas ao uso dos homens, e se opõe a consagrar, que implica retirá-las da esfera do humano - a divinização da mãe de Cristo é um bom exemplo. A religião é aquilo que subtrai algo ao uso comum para transferi-lo a uma esfera separada, do mesmo modo que a teatralidade, que funciona de forma semelhante. $O$ enquadramento implícito em toda operação teatral, que separa quem faz de quem vê, a representação da vida, tem proximidade com o distanciamento do sagrado, o que Agamben reforça quando afirma que não há religião sem separação. Na verdade, o sagrado e o profano são demarcados por um limiar que é preciso atravessar para profanar, em um sentido ou no outro. Segundo o filósofo, o contágio profano é o toque que "devolve ao uso aquilo que o sagrado havia separado e petrificado" (AGAMBEN, 2007, p. 66), como faz Janaína em Stabat Mater, na intenção de restituir à mulher o lugar do comum, do concreto, do corpo emancipado das idealizações do feminino.

Para profanar as imagens petrificadas, Janaína Leite assume as máscaras da maternidade, da sexualidade e da teatralidade "com uma inquieta hesitação perante as formas - e as fórmulas" (AGAMBEN, 2007, p. 66). Habita essas formas para melhor conhecê-las, fazer experiência com elas, fazer uso delas no jogo perigoso da pole dancer grávida que seduz o pai, na exposição da própria mãe em cena, no ato sexual com um profissional da pornografia, na exibição reversa do parto do filho, no relato do estupro que sofreu e na degola da mãe na mesa de conferência. Como se vê, a profanação é o meio que escolhe para trincar as figuras idealizadas da mulher. Ao realizar em cena atos profanos e trabalhar na intersecção entre teatralidade e testemunho, ficção e memória, verdade e artifício, propõe ao espectador o pacto da parresía. E pede coragem para que se enfrente o jogo performativo e político de Stabat Mater, cuja intenção é desativar dispositivos de poder.

\section{Referências bibliográficas}

AGAMBEN, G. Elogio da profanação. In: AGAMBEN, G. Profanações. Tradução: Selvino J. Assmann. São Paulo: Boitempo, 2007. p. 65-80.

EIERMANN, A. El teatro postspectacular. Telondefondo: Revista de Teoría y Crítica Teatral, Buenos Aires, n. 16, p. 1-24, 2012. 
FOSTER, H. O retorno do real: a vanguarda no final do século XX. Tradução: Célia Euvaldo. São Paulo: Cosac Naify, 2014.

FOUCAULT, M. A coragem de verdade. Tradução: Eduardo Brandão. São Paulo: Martins Fontes, 2011.

GUIMARÃES, J. A busca por autonomias instáveis na MITsp 2020. MITsp, São Paulo,

n. 7, p. 260-265, 2020. Disponível em: https://bit.ly/2VFnrlL. Acesso em: 2 jul. 2020. KRISTEVA, J. Stabat Mater. In: KRISTEVA, J. Histórias de amor. Tradução: Leda Tenório da Motta. Rio de Janeiro: Paz e Terra, 1988. p. 269-295

LEITE, J. F. Autoescrituras performativas: do diário à cena. São Paulo: Perspectiva, 2017.

LOURAÇO, J. Figuras de linguagem do indizível em Conversas com meu pai. Sala Preta,

São Paulo, v. 14, n. 2, p. 182-186, 2014. DOI: 10.11606/issn.2238-3867.v14i2p182-186.

MAGRIS, E.; PICON-VALLIN, B. Les théâtres documentaires. Montpellier: Deuxième Époque, 2019.

MARTIN, C. (ed.). Dramaturgy of the real on the world stage. London: Palgrave MacMillan, 2010.

MARTIN, C. Theatre of the real. London: Palgrave MacMillan, 2013.

MENEZES, M. E. A mãe de todas as perguntas. In: Teatrojornal. [S. I.], 1 dez. 2019.

Disponível em: https://bit.ly/3ilChYu. Acesso em: 2 jul. 2020.

RANCIĖRE, J. A partilha do sensível: estética e política. Tradução: Mônica Costa Netto.

São Paulo: Editora 34, 2009.

RANCIÈRE, J. Les bords de la fiction. Paris: Seuil, 2017.

RANCIÈRE, J. O espectador emancipado. Tradução: Ivone C. Benedetti. São Paulo:

Martins Fontes, 2014.

ROMAGNOLLI, L. Este obscuro objeto que deseja. In: ROMAGNOLLI, L.; BELUSI, S.

Horizonte da Cena. Belo Horizonte, 2 mar. 2020. Disponível em: https:// bit.ly/2NPXXhp. Acesso em: 2 jul. 2020.

SAISON, M. Les théâtres du réel. Paris: L'Harmattan, 1998.

SMALL, D. A. A profanação fundamental. Questão de crítica, Rio de Janeiro, v. 11, n. 70, 2019. Disponível em: https://bit.ly/2D3QJnU. Acesso em: 2 jul. 2020.

Recebido em 06/06/2020 Aprovado em 12/06/2020

Publicado em 12/08/2020 